\title{
Lounging with robots - social spaces of residents in care: $A$ comparison trial
}

Kathryn Peri

School of Nursing, The University of Auckland, Auckland, New Zealand

\section{Ngaire Kerse}

Department of General Practice and Primary Care, The University of Auckland, Auckland, New Zealand

\section{Elizabeth Broadbent}

Department of Psychological Medicine, The University of Auckland, Auckland, New Zealand

Chandimal Jayawardena, Tony Kuo and Chandan Datta

Department of Electrical and Computer Engineering, The University of Auckland, Auckland, New Zealand

\section{Rebecca Stafford}

Department of Psychological Medicine, The University of Auckland, Auckland, New Zealand

\section{Bruce MacDonald}

Department of Electrical and Computer Engineering, The University of Auckland, Auckland, New Zealand

Aims: To investigate whether robots could reduce resident sleeping and stimulate activity in the lounges of an older persons' care facility.

Methods: Non-randomised controlled trial over a 12-week period. The intervention involved situating robots in low-level and high-dependency ward lounges and a comparison with similar lounges without robots. A time sampling observation method was utilised to observe resident behaviour, including sleep and activities over periods of time, to compare interactions in robot and no robot lounges.

Results: The use of robots was modest; overall $13 \%$ of residents in robot lounges used the robot. Utilisation was higher in the low-level care lounges; on average, $23 \%$ used the robot, whereas in high-level care lounges, the television being on was the strongest predictor of sleep.

Conclusion: This study found that having robots in lounges was mostly a positive experience. The amount of time residents slept during the day was significantly less in low-level care lounges that had a robot.

Key words: activity, daytime sleeping, interaction, resident, robot, staff.

Correspondence to: Dr Kathryn Peri, School of Nursing, University of Auckland. Tel: 6493737599 extn 82111; Fax: 649 3677158; Email:k.peri@auckland.ac.nz
Introduction

An increasing number of older people in New Zealand live in residential care [1]. For older people living in both lowand high-level of care facilities, social activity and participation are not always maximised [2]. Reduced social activity has been reported as a cause for increased daytime sleepiness in residential care. Frequency of daytime sleepiness is high in nursing homes; previous studies have consistently reported that over $60 \%$ of residents have daytime sleepiness leading to napping [3]. When asked why they thought they slept during the day, older people stated that lack of activities made them sleep; in addition, residents stated that they did not know how to go about being more active in the facility [4].

Daytime sleepiness has been associated with an increased risk of cardiovascular mortality, depression, falls and cognitive deficits [5]. Reducing daytime sleep may improve quality of life for residents as well as improve overall functional ability $[5,6]$.

In New Zealand's residential care, meaningful social activities are legally required by the Health and Disability Sector Standards [7]; however, social programmes vary considerably and there is always a need for innovative ways to engage with older people.

Introducing assistive technology may provide stimulating interactions for older people. Robotics have been used to assist in clinical domains such as blood pressure monitoring [8], in entertainment and communication [9], and for companionship [10,11]. A robot module has been developed in New Zealand for use in residential care and a large study introduced several robots into high-level care lounges to encourage social activities [11]. The questionnaire and interview results of that study are reported in a companion paper (E Broadbent et al., unpublished data, 2014).

The introduction of the robot into the environment of residential care is novel and therefore may have an unpredictable effect. While it is expected that the increased stimulation would have a positive effect, gauging the actual effect is important. As part of a comprehensive implementation of robotics into a retirement village environment, we evaluated the impact of introducing robots into lounges [9]. This paper reports on controlled observation of the activities and interactions of residents, staff and visitors in lounges. Intervention lounges with a robot in place are compared with control lounges without a robot in place. 


\section{Methods}

This study aimed to gauge the impact of the robot on the milieu of activity and behaviour in resident lounges in residential care. A controlled non-randomised comparison study was used to establish the impact of robots in residential care lounges on activities and interactions. Reactions and behaviours (including sleep) were compared between lounges with robots in place and lounges with no robots. The larger trial incorporating individual-level measures and impact on quality of life is reported elsewhere (E Broadbent et al., unpublished data, 2014). Ethics approval was obtained.

\section{Participants}

The residential care wards of Selwyn Village, a retirement complex, were engaged in a large robot trial. This component of the trial reports independent observations of all older people in lounges throughout low level of care wards, sometimes termed rest homes, assisted living or hostel, and highlevel care wards, termed nursing homes, private hospital, or skilled nursing facilities in different countries. Residents, staff and visitors were involved. Because all observations were anonymous and no individuals were approached nor individual data collected, apart from what could be observed from a distance, individual informed consent was not necessary. Management had given consent for the overall project, and all staff, residents and families had been fully informed that the robot project was ongoing in the facility and may involve researchers observing at various times.

\section{Robots}

Preliminary studies indicate that robots can be acceptable to older people in a retirement village [9]. Two types of robot, one chest height and one head height, were stationed in resident lounges for a period of 12 weeks. The functionalities of the robots were the same regardless of size of robot and included: entertainment - music videos, old-time photos, quotes, jokes; brain fitness - questions; communication Skype calls to preprogrammed contacts; vital signs - blood pressure, pulse and pulse oxymetry. The robots talked and displayed information, and the participant gave a response via a touch screen. The robots did not move and were turned on every morning at 0600 and turned off at 2000 hours except in the staff lounge where they remained on 24 hours a day. They were available to be used by staff, activities coordinators, visitors and residents, and could be incorporated into activities.

\section{Robot placement and staff training}

The facility contained two low-level care wards and two high-level care wards. The robots were placed in the two low-level intervention lounges and two lounges in one intervention high-level care ward. The robot was placed so it was easily accessible for interactions. Staff were trained in robot use at staff meetings, residents were trained on site, and a research assistant was available as needed for technical and other advice about the robots. Usual activities also took place in lounges where robots were placed. In the two control lounges, one in high-level care and one in low-level care there were no robots and usual activities were in place.

\section{Observations}

Observations gathered data on all people in the resident lounges or close surrounding areas to record both interactions with and use of the robot, and to compare positive and negative interactions and sleeping behaviour of residents between robot and no robot lounges. Assistants also recorded when residents were sleeping. This was judged by the assistant to be when the resident had his/her eyes closed and was not responding to surroundings.

We adapted Kitson's time sampling observation method from the Quality of Assessment Project (QAP) to observe behaviour and activities over periods of time [12].

\section{Training}

Research assistants were trained to rate interactions between people, and between people and the robot. Set criteria were developed to rate interactions as positive (smiling, talking, participating in activities, surprised, excited, interested, watching) or negative (angry, sad, agitated, frustrated, anxious, afraid and apprehensive). A grading was developed: positive interactions were rated $1+, 2+, 3+$, and negative ones $-1,-2,-3$, depending on the intensity of interaction observed. As part of training, research assistants observed interactions together, rated them and compared ratings in order to establish inter-rater reliability.

The observations were planned as a 'fly on the wall' activity. The researcher would sit in the intervention and control lounges with a clipboard and read a book while observing. It was intended that there would be little interaction between the researcher and the occupants of the room; however, in practical terms politeness necessitated responses to approaches from residents and staff. Occasionally, the researcher was involved in conversations, especially if the robot was present, as residents often had questions. Over time, the residents became used to the researcher being present. Any formal activities such as bingo and newspaper reading continued as usual.

\section{Random selection of observation times and places}

Observations were scheduled for a one hour period anywhere between 0800 and 1800 hours. The time and place were determined using random numbers, so that each lounge area was equally likely to be observed. A standard form was used to record the interactions observed, along with the number of people in the room, any organized activity, whether the robot was present or absent, how many residents, staff and visitors interacted with the robot, or each other, and how many residents were sleeping.

\section{Analysis}

Descriptive statistics were used to describe the number of people in the lounges, number of positive and negative 
interactions, and type of activities. The $\chi^{2}$ test was used to compare the frequency of activities between robot and nonrobot lounges. The time spent sleeping was expressed as: (i) the proportion of residents sleeping at any time per hour of observation; and (ii) by the total number of hours sleeping per resident hour in the lounge at the time of the observation. The rate of positive and negative reactions was calculated as the number of reactions per resident present during the observation at any time; that is, the number of positive (or negative) interactions observed/total number of residents in the area at any time/hour.

The rate of reactions was compared between the robot and no robot groups using $t$-tests. The time residents spent sleeping was recorded in minutes, totalled for each lounge and adjusted by the number of residents in the lounge for the hour of the observation. Total sleeping time/resident was compared between the groups. Rate of sleeping is also presented by any activity type present during the hour.

\section{Results}

\section{Interactions}

In total, 207 observation hours were recorded, 89 in lowlevel care lounges and 118 in high-level care lounges. Table 1 shows the locations of the observations. The total number of residents observed in low-level care was $n=805$ and the number of residents in each observation hour ranged between 0 and 30, with a mean of 7.5 and standard deviation (SD) of 7.2. The total number of residents observed in highlevel care lounges was 752, with a range of 0 to 21 per observation hour and mean of 6.4 (SD 5.3). During 32 observation hours, there was no one in the lounges. The mean number of residents in the robot lounges was 6.5 (SD $6.2)$ and $8.9(8.2)$ in the non-robot lounges.

The overall activities that occurred during observations in total consisted of: viewing TV or videos $(n=50)$, formal activities: games such as bingo $(n=12)$, bowls $(n=6)$, news reading $(n=10)$, word finding $(n=3)$, music $(n=3)$, exercises $(n=4)$, communion $(n=2)$ or reading other than newspapers $(n=2)$ as shown in Table 1 . Breakfast, lunch or morning tea occurred during six observation periods.

Table 2 shows the breakdown of interactions rated by the observers for the levels of care according to the presence of the robot. There was a higher rate of $1+$ positive interactions observed when the robot was present. There was, however, a lower rate of $3+$ positive interactions $(0.2$ vs 0.5 per 10 resident hours). When combining all positive interactions, there were more in robot lounges. There was no difference in the types of interactions observed in high-level care comparing robot and no robot lounges. When both levels of care were combined, there were overall more 1+ positive interaction but there were also more 2- negative interactions occurring in lounges with a robot compared with lounges without a robot. Combining types of reactions in both levels of care, there were more positive interactions ( 7.8 in robot lounges vs 5.7 in no robot lounges) and no difference in the rate of negative interactions observed.

Utilisation of the robot was modest, with $13 \%$ of residents in robot lounges using the robot at all (SD 31\%). Utilisation was higher in low-level care lounges where $23 \%$ on average used the robot (SD 41\%), whereas in high-level care lounges $4 \%($ SD $10 \%)$ used the robot $(\mathrm{t}=-2.99, P=0.01)$.

\section{Sleeping}

During 73 of the total of 207 observations, no one was asleep. The proportion of residents in the lounges that were asleep varied between 0 and $100 \%$, mean $17 \%$ (SD 21\%), and was higher in high-level care home lounges; mean of $21 \%$ sleeping (SD 24\%) vs 11\% (SD 13\%) sleeping in lowlevel care lounges $(F=21.5, P=0.01)$. Total minutes of sleep time/resident hour (the sum of all sleep duration minutes/ total number of residents in the lounge) was on average 3.6

Table 1: Mean number of residents observed in each location per hour, and total hours of observations in each location, descriptions of formal activities in lounges during observations

\begin{tabular}{lcrc}
\hline & Robot & No robot & Total \\
\hline Residents (mean, SD) & & & \\
$\quad$ Low-level care & $5.1(6.8)$ & $18.7(5.5)$ & $9.0(8.9)$ \\
$\quad$ High-level care & $8.1(5.1)$ & $4.7(4.9)$ & $6.4(5.3)$ \\
$\quad$ All residents & $8.5(6.2)$ & $8.9(8.2)$ & $7.5(7.2)$ \\
Observation hours (total) & 63 & 26 & 89 \\
$\quad$ Low-level care & 60 & 58 & 118 \\
$\quad$ High-level care & 123 & 84 & 207 \\
$\quad$ Total & $23(15)$ & $27(32)$ & $50(24) \dagger$ \\
Number of observation hours with these activities occurring & \\
Television or video on & $30(21)$ & $18(27)$ & $48(24)$ \\
Formal activity occurring & $1(1)$ & $3(3)$ & $6(2)$ \\
Exercise class & $5(4)$ & $1(1)$ & $1(3)$ \\
Bowls & $9(7)$ & $1(1)$ & $10(5) \neq$ \\
News reading & $15(12)$ & $13(15)$ & $28(13)$ \\
Other & & & \\
\end{tabular}

$\dagger \chi^{2}=4.2, \mathrm{df}=1, P=0.05 . \mp \chi^{2}=4.3 \mathrm{df}=1, P=0.05$. Other, church, games, wordfind, art, music, reading (excluding newspaper), food; SD, standard deviation. Any Formal activity is the sum of the activities listed, excluding the TV. 
Table 2: Ratings of interactions observed in lounges with and without robots present

\begin{tabular}{|c|c|c|c|}
\hline & Robot & No robot & $\mathrm{T}(P)$ \\
\hline \multicolumn{4}{|l|}{ Low-level care } \\
\hline $\begin{array}{l}3+\text { positive interactions } / 10 \text { residents } \\
2+\text { positive interactions } / 10 \text { residents } \\
1+\text { positive interactions } / 10 \text { residents } \\
\text { Any positive interactions } 10 \text { residents } \\
\text { Neutral interaction } / 10 \text { residents } \\
\text { Any negative interactions } / 10 \text { residents } \\
1 \text { - negative interactions } / 10 \text { residents } \\
2 \text { - negative interactions } / 10 \text { residents } \\
3 \text { - negative interactions } / 10 \text { residents }\end{array}$ & $\begin{array}{l}0.2(0.6) \\
2.6(4.4) \\
6.0(3.8) \\
8.6(5.3) \\
1.9(6.1) \\
1.2(2.7) \\
0.8(1.9) \\
0.7(2.2) \\
0.0(0.1)\end{array}$ & $\begin{array}{l}0.5(0.8) \\
1.3(1.3) \\
3.0(2.6) \\
4.8(3.3) \\
1.3(1.8) \\
0.2(0.2) \\
0.1(0.3) \\
0.0(0.1) \\
0.0(0.0)\end{array}$ & $\begin{array}{r}-2.2(0.03) \\
1.5(0.15) \\
3.4(0.01) \\
-3.2(0.01) \\
0.5(0.60) \\
-2.1(0.04) \\
1.8(0.07) \\
1.6(0.12) \\
0.8(0.40)\end{array}$ \\
\hline \multicolumn{4}{|l|}{ High-level care } \\
\hline $\begin{array}{l}3+\text { positive interactions } / 10 \text { residents } \\
2+\text { positive interactions } / 10 \text { residents } \\
1+\text { positive interactions } / 10 \text { residents } \\
\text { Any positive interactions } / 10 \text { residents } \\
\text { Neutral interaction } 10 \text { residents } \\
\text { Any negative interactions } / 10 \text { residents } \\
1 \text { - negative interactions } / 10 \text { residents } \\
2 \text { - negative interactions } / 0 \text { residents } \\
3 \text { - negative interactions } / 10 \text { residents }\end{array}$ & $\begin{array}{l}0.2(0.6) \\
1.2(2.6) \\
6.4(6.0) \\
7.1(5.2) \\
2.9(3.6) \\
0.9(1.7) \\
0.6(1.2) \\
0.4(1.4) \\
0.0(0.1)\end{array}$ & $\begin{array}{l}0.1(0.2) \\
1.1(2.5) \\
5.4(3.6) \\
6.2(4.5) \\
3.5(3.3) \\
0.8(2.0) \\
0.9(2.1) \\
0.1(0.3) \\
0(0)\end{array}$ & $\begin{array}{r}1.9(0.07) \\
0.22(0.81) \\
1.0(0.33) \\
0.88(0.39) \\
-0.92(0.36) \\
-2.7(0.78) \\
-0.46(0.65) \\
1.4(0.17) \\
0.89(0.37)\end{array}$ \\
\hline \multicolumn{4}{|l|}{ All residential care } \\
\hline $\begin{array}{l}3+\text { positive interactions } / 10 \text { residents } \\
2+\text { positive interactions } / 10 \text { residents } \\
1+\text { positive interactions } / 10 \text { residents } \\
\text { Any positive interaction } / 10 \text { residents } \\
\text { Neutral interaction } / 10 \text { residents } \\
\text { Any negative interaction } / 10 \text { residents } \\
1-\text { negative interactions } / 10 \text { residents } \\
2-\text { negative interactions } / 10 \text { residents } \\
3-\text { negative interactions } / 10 \text { residents }\end{array}$ & $\begin{array}{l}0.2(0.6) \\
1.8(3.6) \\
6.2(5.2) \\
7.8(5.3) \\
2.5(4.9) \\
1.1(2.2) \\
0.7(1.5) \\
0.5(1.8) \\
0.0(0.1)\end{array}$ & $\begin{array}{c}0.2(0.6) \\
1.2(2.2) \\
4.5(3.5) \\
5.7(4.1) \\
2.7(3.1) \\
0.6(1.6) \\
0.6(1.6) \\
0.1(0.3) \\
0(0)\end{array}$ & $\begin{array}{r}-0.26(0.80) \\
1.4(0.16) \\
2.4(0.02) \\
-2.7(0.01) \\
-0.40(0.69) \\
-1.6(0.11) \\
0.71(0.48) \\
2.17(0.03) \\
1.20(0.23)\end{array}$ \\
\hline
\end{tabular}

Table 3: Sleep time comparing activities and levels of care in residential care lounges

\begin{tabular}{|c|c|c|c|c|c|c|c|c|c|}
\hline & \multicolumn{3}{|c|}{ Low-level care lounges } & \multicolumn{3}{|c|}{ High-level care lounges } & \multicolumn{3}{|c|}{ Total } \\
\hline & Act & No act & Total & Act & No act & Total & Act & No act & Total \\
\hline \multicolumn{2}{|c|}{ Minutes/Resident hour } & & $2.0(2.9)$ & & & $4.7(8.4)$ & & & $3.6(6.9)$ \\
\hline Formal & $2.0(2.2)$ & $1.9(3.3)$ & & $6.1(11.1)$ & $4.2(7.3)$ & & $4.1(8.2)$ & $3.3(6.2)$ & \\
\hline TV/Video & $3.8(2.5)$ & $1.6(2.9)^{\star}$ & & $7.0(11.9)$ & $3.4(5.1)^{*}$ & & $6.3(10.5)$ & $2.5(4.3)^{\star \star}$ & \\
\hline Robot & $1.0(1.9)$ & $3.7(3.7)^{\star \star}$ & & $5.6(8.7)$ & $3.6(8.1)$ & & $3.6(6.9)$ & $3.6(6.8)$ & \\
\hline \multicolumn{2}{|c|}{ Proportion sleeping (\%) } & & $11(13)$ & & & $21(25)$ & & & $17(21)$ \\
\hline Formal & $10(15)$ & $12(10)$ & & $20(23)$ & $25(29)$ & & $19(23)$ & $16(21)$ & \\
\hline TV/Nideo & $21(12)$ & $8(13)^{\star}$ & & $27(28)$ & $16(22)^{*}$ & & $26(25)$ & $12(18)^{\star \star}$ & \\
\hline Robot & $4(8)$ & $20(14)^{\star \star}$ & & $26(25)$ & $14(23)^{*}$ & & $17(20)$ & $17(22)$ & \\
\hline
\end{tabular}

${ }^{\star \star} P<0.001$; ${ }^{\star} P<0.05$. Act, named activity present during the hour of observation; Formal, any formal organised activity occurring in the lounges; No act, named activity not present; Proportion sleeping, proportion of residents asleep in the lounge during the observation hour; TV, television. One hundred fifty-nine observation sessions were included

minutes (SD 6.9, max 55 minutes) and differed between low-level and high-level care; 4.7 minutes/resident hour (SD 8.4) in high-level care lounges versus 2.0 minutes/resident hour (SD 2.9) in low-level care lounges.

Table 3 shows that the amount of sleep and proportion of people sleeping in the lounges was greater when the TV was on, and less when the robot was present in low-level care lounges. The variability in the amount of sleep and proportion of sleepers was large. Using generalised linear regression with the minutes of sleep per resident hour as the dependent variable, the amount of sleep was least in low-level care lounges when the robot was present $\left(\chi^{2}=9.4, P=0.01\right)$, independent of other formal activities and the television being on. TV viewing was not significantly associated with sleep time in low-level care lounges when the robot was present. Whereas in high-level care lounges, the television being on was the strongest predictor of sleep time $\left(\chi^{2}=6.5\right.$, $P=0.01)$ and the robot was not associated with sleep controlling for the television use.

\section{Discussion}

This study presents a unique opportunity to observe the effects of having a robot situated in high-level and low-level 
care lounges. It was found that having robots in lounges was mostly a positive experience for the residents, staff and families; however, it was noted that negative interactions were recorded when the robot was present in high-level care lounge areas, where residents require higher levels of nursing care. Residents were less likely to interact with the robot potentially because of the robot's touch screen functionality. The robot's touch screen functionality was problematic for residents who had difficulty reaching the screen due to their wheelchair design. Providing closer proximity, and/or alternate means of interaction, will be important when designing robots for older people to ensure that robotic functions can cope with individual differences and specific needs [13].

In our trial, the response to the robot was mixed, with an overall higher rate of positive interactions observed in robot lounges. Human interactive robots designed for entertainment, and social activity and education have been shown to have positive and therapeutic effects on older people in the trials. For example, an experiment in a care facility found that Paro, a seal robot, increased the social interactions as well as improved stress levels, as measured by hormones in older people's urine after interaction with Paro [10,11]. A recent randomised controlled trial showed that Paro decreased loneliness and increased communication among residents and staff [11]. A pilot study of a mobile robotic assistant designed for older people in assisted living facilities demonstrated a positive experience in such activities as providing appointment prompts and geographical guidance to residents [13].

Human interactive robots for psychological enrichment have been shown to be effective in entertaining people by playing games (e.g. memory games) and music that will stimulate their minds [10]. Our trial supports previous work showing that robots may be a new method of mental healthcare for older people. A number of robot therapies introduced to the older population in care facilities have required caregiver initiation and ongoing support [10]. The Guide robot introduced into the lounges in this trial produced interactions that were, on the whole, positive and entirely self managed by the residents. A study conducted in a public area of a care facility using a mobile nursing robot 'Pearl', successfully provided reminders to residents and guidance around the facility for residents with cognitive impairment [13].

Considering the low-level care results, there were more positive than negative interactions with the robot, suggesting that the robot was a socially stimulating experience for residents living in low-level care wards. There was more utilisation in low-level care lounges supporting this result. There was also less sleep occurring in low-level care lounges when the robot was there, regardless of whether the TV was on.

This may suggest that the design of the robots was sophisticated enough for low-level care residents to find the interaction enjoyable, but not high-level care residents. Perhaps the robot is a point of interest and provides added stimuli for the higher-functioning residents. It is important that the robot be compatible with human needs and is not only understandable, but can provide the interactional support that a human expects. The challenge will be to create user experiences that will encourage long-term usage [14].

An interesting finding from the observations was that the amount of time residents spent sleeping during the day was significantly less in low-level care lounges that had a robot. Sleep studies in long-term care have shown that excessive daytime sleeping significantly disrupted night-time sleep and created abnormal circadian rhythms. Martin et al.'s study reported that residents with poor daytime and night-time sleeping patterns were more likely to spend over a third of their time in the bedroom, seldom went outside, and participated less in physical and social activities [6]. Getting robots to interact with these individuals may provide a valid way to increase activity levels. The Guide robots used in this trial have the ability to move through the facility, so targeted residents could easily receive a daily dose of robot therapy in their rooms, as well as robots being used in the care lounges.

Generally, residents have the opportunity to participate in meaningful social activities, usually organised by an activities coordinator. The person ensures that a wide range of activities is offered so residents can involve themselves with various social and individual personalised activities. In our study, there was no difference in the sleeping time or proportion of people sleeping in lounges whether there was an activity going on or not. However, the television appeared to increase sleep time markedly, especially in high-level care lounges. More specifically, the results showed that less planned formal activities occurred in the high-level care lounges compared to low-level care lounges.

This study has several limitations. Firstly, the researcher recording the observational interactions was often asked to assist residents with the robot functions, which may have increased the positive interactions to the robot. Being a fly on the wall in this trial posed difficulties as the researchers and observers were the same individuals. Future research could use an unassociated observer to allow more independent observations. A more independent method may be videorecording the unattended robot; however, this was beyond the scope of this project: residents at the village expressed a desire not to be constantly video recorded, for privacy reasons. This may be something to be considered in future robotic observational studies. Secondly, we trialled only one type of robot in the lounges; the use of other robots such as the IRobqi and Cafero may be more acceptable to and usable by the residents. Thirdly, the trial was not randomised and thus there may have been imbalance in the types of residents involved in each facility. Participants in the questionnaire part of the study did exhibit higher activities of daily living and dependency behaviour scores in the robot areas at baseline. There were more robot lounges and thus more robot 
observations in the low-level care wards than observations with no robot. Presenting the results as rates and selecting random times for the observations may alleviate this limitation. Generalisability is limited as there was only one facility involved in this trial. Further research challenges relate to the difficulties determining which measures would be the most useful or appropriate for evaluating 'social effectiveness' in robot trials.

\section{Conclusion}

In conclusion, this study has shown that integration of a robot into the environmental milieu in older persons' care has a modest stimulating effect on sleep and positive and negative interactions for the residents in low-level, but not high-level care wards. However, assistive technology such as robotics should be considered an important developmental area in the older persons' care sector.

\section{Acknowledgements}

The authors would like to thank the retirement village for their cooperation and their support. This work was jointly supported by the Robot Pilot Project programme of the Korea Ministry of Knowledge and Economy (MKE), Korea Institute for Robot Industry Advancement (KIRIA) and the New Zealand Ministry of Business, Innovation and Employment IIOF (13635). We would also like to thank ED/Isan and Yuiin for the Guide and Cafero robots and their technical support, and our colleagues at the University of Auckland HealthBots research team for their ongoing support.

\section{Key Points}

- This study found that having robots in lounges was a positive experience for residents, staff and families.

- More positive interactions occurred with robots in low-level wards.

- Having the television on in high-level wards was the strongest predictor of daytime sleeping.

\section{References}

1 Statistics New Zealand. National Population Projections: 2009-2061. Wellington 2009.

2 Kane RA. Long-term care and a good quality of life: Bringing them closer together. The Gerontologist 2001; 41: 293-304.

3 Rao V, Spiro J, Steele C et al. Insomina and daytime sleepiness in people with dementia residing in assisted living: Finding from the Maryland Assisted Living Study. International Journal of Geriatric Psychiatry 2008; 23: 199-206.

4 Ancoli-Israel S, Martin J. Insomnia and daytime napping in older adults. Journal of Clinical Sleep Medicine 2006; 15: 333-342.

5 Gooneratne N, Weaver T, Cater J et al. Functional outcomes of excessive daytime sleepiness in older adults. Journal of the American Geriatrics Society 2003; 51: 642-649.

6 Martin J, Webber A, Alam T, Harker J, Josephson K, Alessi CA. Daytime sleeping, sleep disturbance, and circadian rhythms in the nursing home. The American Journal of Geriatric Psychiatry 2006; 14: 121-129.

7 Ministry of Health. Health \& Disability Sector Standards. NZS 8134.0:20082008. 2008.

8 Broadbent E, Kuo I, Stafford RMQ, Kerse NM, MacDonald BA. How do older persons respond to a blood pressure robot? Paper presented at New Zealand Association of Gerontology and Age Concern New Zealand Conference; Wellington, New Zealand; 2009.

9 Broadbent E, Tamagawa R, Patience A. Attitudes towards healthcare robots in a retirement village. Australian Journal on Ageing 2011; 31: $115-120$.

10 Shibata T, Wada K. Robot therapy: A new approach for mental healthcare of the elderly - a mini review. Gerontology 2011; 57: 378-386.

11 Robinson H, Macdonald B, Kerse N, Broadbent E. The psychosocial effects of a companion robot: A randomized controlled trial. Journal of the American Medical Directors Association 2013; [Epub ahead of print]; March.

12 Norman IJ, Redfern SJ, Oliver S, Tomalin DA. Evaluation of Kitson's therapeutic nursing function matrix in the assessment of quality of nursing care in hospital. International Journal of Nursing Studies 1994; 31: 337-348.

13 Pineau J, Montemerlo M, Pollack M, Roy N, Thrun S. Towards robotic assistants in nursing homes: Challenges and results. Robotics and Autonomous Systems 2003; 42: 271-281.

14 Fong T, Nourbakhsh I, Dautenhahn K. A survey of socially interactive robots. Robotics and Autonomous Systems 2003; 42: 143-166. 